\title{
EDITORIAL
}

\section{Conditioned responses in pharmacotherapy research ${ }^{1}$}

At a descriptive level, the response to inert or therapeutically irrelevant substances or placebos can be viewed as a conditioned response. The notion that a placebo is a conditioned stimulus is not new and conditioning remains one of the primary but least studied analyses of the 'placebo effect'. In behavioural terms, the physiological (and therapeutic) effects unconditionally elicited by drugs are unconditioned responses; the drug itself may be referred to as the unconditioned stimulus (UCS). Environmental or behavioural events or stimuli that are neutral with respect to the unconditioned effects of drugs and either purposely or coincidentally are associated with and reliably precede the administration of drug, including the 'pill' or injection, itself, may be referred to as conditioned stimuli (CS). Thus, the response to an inert (or therapeutically irrelevant) substance or placebo has been described as a conditioned response. Several investigators have hypothesized that the entire ritual associated with drug administration can take on the properties of a conditioned stimulus by virtue of the repeated association of these neutral events with the unconditioned effects of drug administration in the history of the patient. Recent reviews of this literature have been provided by Wickrameskera (1980), White et al. (1985), Gadow \& Poling (1986) and Ader (1988). Also, numerous studies, reviewed by Harris \& Brady (1974) and Eikelboom \& Stewart (1982), have documented conditioned pharmacological responses; that is, after one or more injections of drug, the behavioural and physiological effects of the pharmacological agent could be elicited by an injection of saline, the CS (a placebo) alone, and several of these authors (e.g. Herrnstein, 1962; Ross \& Schnitzer, 1963; Lang et al. 1967; Pihl \& Altman, 1971; Roffman et al. 1973; Deutsch, 1974; Numan et al. 1975; Hayashi et al. 1980) have implicated conditioning in the 'placebo effect'.

If the placebo effect is the result of conditioning, what are the therapeutic implications and what are the implications for psychopharmacological research? At present, studies designed to evaluate drug effects involve two groups. No matter how the dose, route of administration, frequency, or duration of treatment is varied, an experimental group receives active drug and a control group does not. Adopting a behavioural perspective, the experimental group can be described as being on a continuous or $100 \%$ reinforcement schedule, i.e. stimuli invariably associated with drug administration are consistently followed (reinforced) by the unconditioned effects of the drug. The control group, however, engages in the same behaviours and is subjected to the same environmental cues but is never reinforced, i.e. the control group is on a $0 \%$ reinforcement schedule. One is therefore prompted to ask about the efficacy of reinforcement schedules between 0 and $100 \%$. There is, evidently, an alternative to the evaluation of drug effects by administering drug or placebo: one can administer drug and placebo. In doing so, the schedule of pharmacological reinforcement becomes an alternative means of titrating cumulative drug dose, and, by capitalizing on conditioned pharmacotherapeutic responses, it might be possible to maintain some physiological state within homeostatic limits using lower cumulative amounts of drug.

The heuristic value of viewing a regimen of drug therapy as a series of conditioning trials derived from a study that attempted to capitalize on conditioned immunosuppressive responses in the pharmacotherapy of autoimmune disease in mice genetically prone to the development of a lupuslike disorder (Ader \& Cohen, 1982). In addition to a group of animals that received weekly pairings of saccharin (CS) and the immunosuppressive drug, cyclophosphamide (CY), the UCS, another group of (conditioned) animals was treated on a $50 \%$ reinforcement schedule. These mice were

\footnotetext{
1 Address for correspondence: Dr Robert Ader, Department of Psychiatry, University of Rochester School of Medicine and Dentistry, Rochester, NY 14642, USA.
} 
exposed to saccharin weekly but received CY on only half the trials (on the remaining trials they were exposed to the CS plus an injection of saline). The development of disease and mortality were significantly delayed in these conditioned mice relative to an untreated group and relative to a nonconditioned group that received the same number of exposures to saccharin and to CY, but in an unpaired manner. These latter two groups did not differ. Thus, re-exposure to a CS paired with active drug potentiated the effects of a treatment regimen that was not, by itself, sufficient to alter the course of the autoimmune disease. When active drug treatment was discontinued, mice that continued to be re-exposed to the CS survived significantly longer than a conditioned group that experienced neither the drug nor the CS. In fact, animals that continued to be exposed to the CS did not differ from animals that continued to receive active drug (Ader, 1985).

Most studies of the placebo effect have addressed the variables that could influence the initial response to inert substances. However important, these acute effects, influenced in part by the size, colour, and shape of the pill, the sex and age of the patient, and, prominently, the patient-physician relationship, may not be sufficient for a full understanding of the long-term therapeutic potential of the placebo effect. Some experimental and clinical studies have interspersed drug and placebo treatments, but, as far as I know, no studies have systematically varied the schedule of pharmacological reinforcement in examining the efficacy of different therapeutic regimens. There are, however, clinical observations that are relevant to a conditioning interpretation of the placebo effect although they are not usually cited in this context. Greenberg \& Roth (1966), for example, successfully reduced the amount of tranquillizing drug given to schizophrenics by substituting a placebo for active drug on a gradually increasing number of days per week. Also, while there are exceptions, several studies have implicated learning processes in the therapeutic response to drugs in showing that the effect of placebo treatment is greater when it follows rather than precedes effective drug therapy (Sunshine et al. 1964; Batterman, 1965; Moertel et al. 1976). In this regard, it has been noted that patients receiving placebo following active drug treatment display drug effects that persist for a period of time that exceeds the known residual effects of the drug (e.g. Batterman, 1966). Such effects may be attributable to indirect residual drug effects, but they may actually reflect conditioning since these patients are being re-exposed to a CS repeatedly paired with effective drug treatment in the immediate past (Ader, 1989). Recent data obtained from hypertensive patients who were given placebo or no treatment following a period of effective drug therapy are consistent with the latter interpretation (Suchman \& Ader, 1992). That is, the maintenance of reduced blood pressures could not be attributed to the residual effects of the drug as defined by the 'no treatment' group.

Conceptualizing a pharmacotherapeutic regimen as a series of conditioning trials suggests new strategies for assessing drug and placebo effects and testable hypotheses that derive from a learning perspective. Central among these would be the institution of different schedules of pharmacological reinforcement or variation of the active drug:placebo ratio. Under a prolonged regimen of pharmacotherapy, cumulative drug dose might thus be titrated, not by a gradual reduction or increase of the concentration of drug administrated on each of the component drug trials, but by a change in reinforcement schedule. Some of the potentially relevant clinical issues that need to be addressed have been discussed elsewhere (Ader, 1988). One could not expect conditioning to occur in replacement therapies, i.e. in those situations in which drugs are prescribed to replace what a target organ is unable to provide. However, such a strategy has several possible advantages in a number of other clinical situations. If a partial schedule of reinforcement can approximate the therapeutic effects of a continuous schedule of reinforcement, total drug dose would be reduced, some side effects might be reduced (which might, incidentally, increase adherence to the pharmacotherapeutic regimen), dependence problems might be reduced or more easily alleviated, and the duration of pharmacotherapeutic effects might be extended. Also, the costs of medication would be reduced.

ROBERT ADER

Preparation of this paper was supported by a Research Scientist Award (K3-MH06318) from the National Institute of Mental Health. 


\section{REFERENCES}

Ader, R. (1985). Conditioned immunopharmacological effects in animals: implications for a conditioning model of pharmacotherapy. In Placebo: Theory, Research and Mechanisms (ed L. White, B. Tursky and G. Schwartz), pp. 306-323. Guilford: New York.

Ader, R. (1988). The placebo effect as a conditioned response. In Experimental Foumdations of Behavioral Medicine: Conditioning Approaches (ed. R. Ader, H. Weiner and A. Baum), pp. 47-66. Lawrence Erlbaum: Hillsdale, NJ.

Ader, R. (1989). Conditioning effects in pharmacotheraphy and the incompleteness of the double-blind, crossover design. Integrative Psychiatry 6, 165-170.

Ader, R. \& Cohen, N. (1982) Behaviorally conditioned immunosuppression and murine systemic lupus erythematosus. Science 215, 1534-1536.

Batterman, R. C. (1965). Methodology of analgesic evaluation: experience with orphenadrine citrate compound. Current Therapy Research 7, 639-647.

Batterman, R. C. (1966). Persistence of responsiveness with placebo therapy following an effective drug trial. Journal of New Drugs 6 , $137-141$.

Deutsch, R. (1974). Conditioned hypoglycemia: a mechanism for saccharin-induced sensitivity to insulin in the rat. Journal of Comparative Physiology and Psychology 86, 350-358.

Eikelboom, R. \& Stewart, J. (1982). Conditioning of drug-induced physiological responses. Psychological Review 89, 507-528.

Gadow, K. D. \& Poling, A. D. (eds.) (1986). Methodological Issues in Human Psychopharmacology: Advances in Learning and Behavioral Disabilities (Suppl. I). JAI Press: Greenwich, CT.

Greenberg, L. M. \& Roth, S. (1966). Differential effects of abrupt versus gradual withdrawal of chlorpromazine in hospitalized chronic schizophrenic patients. American Journal of Psychiatry 123, $221-226$.

Harris, A. H. \& Brady, J. V. (1974). Animal learning - visceral and autonomic conditioning. Annual Review of Psychology 25, 107-133.
Hayashi, T., Ohashi, K. \& Takadoro, S. (1980). Conditioned drug effects to d-amphetamine and morphine-induced motor acceleration in mice : experimental approach for placebo effect. Japanese Journal of Pharmacology 30, 93-100.

Herrnstein, R. J. (1962). Placebo effect in the rat. Science 138, $677-678$

Lang, W. J., Ross, P. \& Glover, A. (1967). Conditional response induced by hypotensive drugs. European Joturnal of Pharmacology 2, 169-174.

Moertel, C. G., Taylor, W. F., Roth, A. \& Tyce, F. A. (1976). Who responds to sugar pills? Mayo Clinic Proceedings 51, 96-100.

Numan, R., Smith, N. \& Lal, H. (1975). Reduction of morphinewithdrawal body shakes by a conditioned stimulus in the rat. Psychopharmacology Communications 1, 295-303.

Pihl, R. O. \& Altman, J. (1971). An experimental analysis of the placebo effect. Journal of Clinical Pharmacology 11, 91-95.

Roffman, M., Reddy, C. \& Lal, H. (1973). Control of morphinewithdrawal hypothermia by conditioned stimuli. Psychopharmacologia 29, 197-201.

Ross, S. \& Schnitzer, S. B. (1963). Further support for the placebo effect in the rat. Psychological Reports 13, 461-462.

Suchman, A. \& Ader, R. (1992). Placebo responses in humans are shaped by prior pharmacologic experience. Psychosomatic Medicine 51, 251 .

Sunshine, A., Laska, E., Meisner, M. \& Morgan, S. (1964). Analgesic studies of indomethacin as analyzed by computer techniques. Clinical Pharmacology and Therapeutics 5, 699-707.

Wickrameskera, 1. (1980). A conditioned response model of the placebo effect: predictions from the model. Biofeedback and Self Regulation 5, 5-18.

White, L., Tursky, B. \& Schwartz, G. (eds.) (1985). Placebo: Theory, Research and Mechanisms. Guilford: New York. 